Bryn Mawr College

Scholarship, Research, and Creative Work at Bryn Mawr College

Graduate School of Social Work and Social

Graduate School of Social Work and Social

Research Faculty Research and Scholarship

Research

2011

\title{
Conflict, health care and professional perseverance: a qualitative study in the West Bank
}

Cindy A. Sousa

Bryn Mawr College, csousa@brynmawr.edu

Amy Hagopian

Let us know how access to this document benefits you.

Follow this and additional works at: http://repository.brynmawr.edu/gsswsr_pubs

Part of the Social Work Commons

\section{Custom Citation}

Sousa, Cindy and Hagopian, Amy. "Conflict, health and professional perseverance: Effects of military occupation on healthcare delivery in the West Bank". Global Public Health 6.5 (2011), 520-533.

This paper is posted at Scholarship, Research, and Creative Work at Bryn Mawr College. http://repository.brynmawr.edu/gsswsr_pubs/53

For more information, please contact repository@brynmawr.edu. 


\begin{abstract}
The past three decades have been a time of considerable global conflict, affecting over 50 countries and causing substantial impacts on civilian health. While many effects are direct results of violence, conflict also impinges on health through indirect means. The restricted mobility of health care staff and patients, targeting of health care workers, and stressful working conditions disrupt the ability of health care workers in conflict zones to function effectively. This paper explores the challenges experienced by health care workers in West Bank, Palestine, as well as their strategies of persistence. Research activities included participant observation and interviews with health care providers, which were then analysed for common themes.

Results demonstrated that the Israeli military occupation of the West Bank considerably impacts civilians' access to both urgent and preventive care. While attempting to deliver care, providers encountered disruptions, harassment and violence, which interrupted care and contributed to job stress. Professional perseverance was evident, but its influence was limited by enduring constraints. This study thus underscores the importance of accountability to international law regarding the rights of civilians to health care in conflict zones. Health professionals may play a particular role in advocating for just and dignified resolutions to conflicts.
\end{abstract}

\title{
Introduction
}

The past three decades have been a time of considerable global conflict and war, affecting more than 50 countries and substantially affecting the health of civilians (Baingana et al. 2005, WHO 2002). The impacts of conflict on health care have been studied in a myriad of locations, including the Democratic Republic of Congo, Somaliland, East Timor, and Northern Pakistan 
(Herp et al. 2003; Leather et al. 2006; Marlowe and Mahmood, 2009; Varley, 2010). These studies, as well as a report by the World Health Organization, note that political conflict can threaten health care services through its effects on infrastructure, human resources, equipment and supplies, relief and health care activities, formulation of health policy, and access to care (World Health Organization (WHO), 2002).

This study examined the problems with health care service delivery in the West Bank, part of the Occupied Palestinian Territories, a region well-known for its history of protracted conflict (for historical timeline of the conflict and an analysis of its relationship to health see, for instance, Giacaman et al. 2009, and other articles in the Lancet series on health in Palestine). About 3.5 million Palestinians currently live in the Occupied Palestinian Territories; of these, more than 2.5 million live in the West Bank (CIA World Factbook, 2008). The West Bank, in contrast to many other areas of conflict, is the site of persistent military occupation of civilian areas, which began in 1967 (Becker et al. 2009; Giacaman et al. 2009). Scholars consider the health care system highly fragmented, a result of assorted funding and administrative arrangements (Giacaman et al. 2003; Hamdan et al. 2003). It has been suggested that this fragmentation is part of a strategy of de-development, 'the deliberate, systematic deconstruction of an indigenous economy by a dominant power (Roy, 1995)'. Through this process, government systems are crippled. As a result, health care becomes increasingly overloaded and difficult to access. Although fragmentation and de-development are clearly issues to be addressed, scholars suggest there might be adequate health care coverage for the population if freedom of movement were a reality (Hamdan et al. 2003). However, since the conflict in the region is in part distinguished by considerable impediments to movement due to checkpoints, roadblocks, and the 
requirements for permits and 'coordination' to pass, interruptions to health care are common. Rural communities are especially affected.

Most recently, construction began in 2002 of an 8-metre high, 436-mile long concrete separation wall. The International Court of Justice declared this wall illegal in 2004. While court decisions have effectively challenged some of the planned routes, Israel persists in continuing the project, maintaining that it is a necessary response to attacks on Israeli cities and towns (Israel Ministry of Foreign Affairs, 2004).

(Figure 1)

Figure 1 (United Nations Office for the Coordination of Humanitarian Affairs (UNOCHA)-Occupied Palestinian Territories (oPt), 2008b) shows the Israeli military presence in the area and illustrates the route of the separation wall in 2008 (the bulk of data collection was done June to August 2007). The heavy solid line represents the completed portion of the wall during the time of the map's publication; interruption by a dotted line represents areas of the wall in the process of construction. The thinner line (between what are marked as the West Bank, in either white or lighter grey, and Israel, in darker grey) shows the Armistice Line, the agreed-upon 1948 borders of Israel. The circles illustrate checkpoints in the West Bank; grey shaded areas represent portions of the West Bank inaccessible to Palestinians, or subject to restrictions. In 2007, more than one-third of the West Bank consisted of Israeli infrastructure (United Nations Office for the Coordination of Humanitarian Affairs (UN-OCHA)-Occupied Palestinian Territories (oPt), 2007b). According to a 2007 United Nations report, there were 539 barriers in the West Bank, including 74 staffed checkpoints, 87 road barriers, 90 road gates and 56 concrete roadblocks (United Nations Office for the Coordination of Humanitarian Affairs (UN-OCHA)-Occupied Palestinian Territories (oPt), 2007a). 
The Israeli checkpoints and road blocks, separation wall, and military presence limit access to medical equipment and medicine, compromise the education of health care professionals, and block access to both preventive and curative health services (Palestine Monitor, 2011; UNICEF, n.d.). The isolation and fragmentation of health care due to the Israeli wall impairs provision for $20 \%$ of the population in the West Bank (Jubran, Al Faqih, Nafe, Khalili, \& Barghouthi, 2005). Between January 2007 and April 2008, medical personnel encountered 929 incidents at checkpoints, resulting in a loss of over 11,000 work-hours (United Nations Office for the Coordination of Humanitarian Affairs (UN-OCHA)-Occupied Palestinian Territories (oPt), 2008a). This research study examines the consequences of and resistance to problems with health care delivery in a region with considerable, ongoing conflict. It explores three questions: What are the experiences of health care providers working in conflict zones with inhibited health care delivery? What are the consequences of this? How do providers respond to these challenges?

\section{Methods}

This research was conducted in partnership with the Palestinian Medical Relief Society (PMRS), a Palestinian health care NGO. The University of Washington's Human Subjects Division approved the data collection process. Data collection included participant observation, analysis of secondary data, and semi-structured interviews with key informants. The majority of data collection occurred in the West Bank during the summer of 2007, with follow-up in 2008 and 2009. Various measures were employed to enhance the rigour of the research (e.g. member checking and triangulation of data), as suggested by scholars of qualitative health research (Devers, 1999). 
Participant observation consisted of accompanying PMRS in 10 mobile clinics, travelling with medical personnel attempting to transfer a patient to a specialty care clinic, observing activities at the Ministry of Health (MOH) and PMRS standing clinics, travelling and working with health care administrators daily for over 10 weeks, and shadowing PMRS' mental health teams to observe group and individual sessions. Procedures also included at least 50 participant observations at checkpoints in the West Bank. During checkpoint observations, information was collected on wait time, number of vehicles waiting, the presence of ambulances in the queue, behaviour of Israeli soldiers, and any special occurrences (i.e. apparent harassment, detentions).

Throughout participant observation, informal discussions occurred with health care providers (doctors, laboratory technicians, nurses and community health workers), ambulance drivers, health care administrators and mental health workers. These interactions were recorded in field notes. Field notes also included photographs of checkpoints and dealings that were used to explore the spatial interactions between civilian health workers and military personnel. Eight semi-structured key informant interviews were conducted with administrators, doctors and ambulance drivers. Interviews took place in English, and extensive notes were taken. Secondary data from PMRS' mobile clinic programme was also analysed, such as incident reports that recorded occurrences workers experienced at checkpoints. Data included number of staff involved, location of the incident, purpose of the trip, reason for the incident (curfew, insistence on searching, no apparent reason, etc.) and parties responsible for the incident (Israeli Defense Forces, Israeli Border Police, settlers, Palestinian Authority, etc.). Textual and visual data were analysed for themes.

\section{Results}


Three main themes emerged: the systematic challenges created by the closures, the impacts of these and other Israeli practices and policies on health and health care delivery, and strategies providers employ to manage the task of health care delivery under these extremely stressful conditions.

\section{Challenges medical personnel encounter: delays, searches and abuse}

Medical personnel encountered delays, searches, harassment and abuse. These occurred primarily at checkpoints, but also in other venues.

(Figure 2)

\section{Delays and searches}

Delays, which often included searches of vehicles and personnel in addition to examinations of drivers' documents, emerged as a common impediment to health care workers attempting to deliver services. At least 50 checkpoints were monitored by the lead researcher, with delays at almost every one of them ranging from two minutes to a half hour. Regular delays were experienced of around fifteen minutes, and often longer depending on the number of vehicles in the queue and the practices of the authorities at the checkpoints regarding identification requirements for drivers and passengers in both private vehicles and in vehicles used for health care provision. Figure 2, for example, shows one checkpoint where more than 50 cars waited to pass. At checkpoints, PMRS drivers were routinely required to show identification for every passenger in the vehicle. Occasionally, a checkpoint was empty or the soldier simply waved the team through, but this was the exception. Ambulance drivers described waits of up to three hours and times when they were not allowed access to their patients either entirely or without significant interruption. On one observed trip, a PMRS vehicle was stopped at five different checkpoints while trying to reach patients. One driver recounted: 
'Last week, I was trying to get through Hawara checkpoint. The total trip took me about 5 to 6 hours. I was at the checkpoint for 2 hours. There was a patient who had just had open-heart surgery and he was going to the hospital for a check-up. The soldier at the checkpoint said I didn't have the proper licence to get through and made us wait in the hot sun. This past week was very hot, and the soldiers made the ambulances stop in the sun; this was very bad for patients'.

Workers were frequently mandated to leave the vehicle to stand for inspection. They were often commanded to open each door of the vehicle and to open its various compartments. On another observed trip, a PMRS vehicle was stopped and searched at least twice while trying to transport a girl of about 7 or 8 years and her mother to a clinic for specialised care. Although under international law medical providers should be allowed expedited passage, waits at checkpoints were commonplace. Palestinian health care workers also expressed reluctance to exercise this right in the midst of the misery of others who were obligated to wait.

Delays created by the checkpoint system resulted in the deaths of Palestinian patients. Ambulance drivers reported having problems reaching patients in time during emergencies, noting there were times that patients died because they could not get through checkpoints in an expedited fashion. In one interview an ambulance driver said, 'There were times I couldn't get to patients and they bled to death'. A driver recounted:

'While I was driving, two tanks stopped my ambulance and blocked me. Two to three soldiers were shooting at the ground and the sky. They told me to get out with my hands up. Then the soldiers strip-searched me; they made me take off all my clothes. The soldiers made me stay two hours in the hot sun. They turned off the ambulance, so there was no air conditioning for the patient. I kept begging them to let me go check the patient. Finally, they let me. When I went to check the patient's pulse, I realised that he had died'.

Besides preventing immediate service delivery, delays at checkpoints affected the administrative duties of health care planners and managers, as site visits or meetings became allday commitments due to road closures and checkpoint delays. For example, PMRS health care 
providers and administrators were scheduled to attend a meeting with international donors in Nablus, a town two districts away. Israeli military personnel at the checkpoint into Nablus refused entry to the administrators, even though they were riding in an official PMRS vehicle. This resulted in having to move the meeting to a different town. In total, travel to the meeting with international donors took almost seven hours due to the restrictions imposed at the checkpoints. Other effects were also noted in terms of delays. For instance, supervisors often could not reach clinics to provide oversight or to meet with clients who had more specialised needs. These visits were all-day commitments, and often included more time for travel due to the restrictions than for actual service delivery. Hence, caseloads and schedules of clinics and providers were often affected.

According to the incident logs reviewed, the most common reason for delays in care were searches of personnel and the vehicle, medications and property. Other reports stated there was 'no apparent reason' for the delay, simply that personnel were kept waiting. Most of the reports noted that PMRS staff had provided the Israeli soldiers a 'facilitation letter' signed by a Spanish NGO that supports their mobile clinic project, but were still denied access. One report stated that the mobile clinic team contacted the Israeli Authorities, the Spanish Cooperation Office, the Spanish Consulate and UN-OCHA in an attempt to facilitate access. In this instance, access was granted on the condition that the next mobile clinic to the village would require written permission from the Israeli authorities in addition to the Spanish coordination letter.

(Figure 3)

\section{Abuse and harassment}

Ambulance drivers and medical personnel reported numerous incidents of personal violence and threats. Interviewees described that medical personnel were targeted and subjected to outright 
harassment at checkpoints during provision of services and at PMRS headquarters. These

accounts included reports of being taken from the PMRS administrative building and used as a

human shield for an incursion into a neighbouring building, physical and verbal aggression from

soldiers at checkpoints, and arrests during attempts to deliver care. One PMRS doctor described:

'During the first Intifada, I was working in [a small village]. There were 50,000 people under continuous curfew for 11 days. I used to sneak to the village for those days [to provide health care]. When I was caught by soldiers, I was threatened to be shot in the health centre itself-despite the Red Crescent head coming. I was under fire several times in this area. I remember negotiating with Israeli IDF [Israeli Defense Forces] officers:

"Well, you don't want me to open the centre?..."

The Director of the Emergency Programme at PMRS noted continual violations against

his team. These ranged from strip searches to assaults at checkpoints. One ambulance driver described being delayed at a checkpoint, and then forced to get out of the ambulance and finally being slammed into his vehicle by the soldier:

'I was driving the mobile clinic and I was trying to get through a checkpoint. The soldier said I couldn't go through. I was arguing with them, and trying to tell them that I had doctors and medicine with me and I needed to pass. I had to get out of the ambulance. The soldier put my arms behind my back and slammed me into the glass on the ambulance. In the end, they would not let us pass through and we had to turn back'.

Data illustrated acute incidents of abuse. They also demonstrated continual, low-level stress as a result of encounters with Israeli soldiers. Providers described tactics of the Israeli occupation, including the impediment to freedom of movement at checkpoints and road closures, as humiliating. Interviewees reported being targeted for degradation and abuse because they were medical providers. One doctor said, 'At checkpoints they try to humiliate you because you are a doctor'.

\section{Effects of closure policy}

Impacts on primary care

Participants were asked about the impacts of the conflict on health services in general. Israeli closure policies, including checkpoints, road re-routing, and regular sieges of entire villages, 
were clearly a barrier to delivering critical, acute care. Some participants detailed these impacts, especially the ambulance drivers. However, most interviewees were more inclined to detail the effects of the occupation on the provision of primary care.

Mobile clinics were set up at local community centres, schools and mosques to screen and treat chronic diseases such as diabetes and hypertension, offer well-baby and well-mother visits, and provide vaccinations and other primary care services. In the absence of the mobile clinics, patients had to endure difficult travel around road closures and through checkpoints to reach a clinic. Often, PMRS' mobile clinics provided the only on-site medical care for people in certain villages. The denial or delay of mobile clinic access was thus even more urgent when taking into account the many villages that were effectively sealed off and left without any type of medical services.

The Director of the Emergency Programme stressed that while many programmes provided primary care for Palestinians, they could not compensate for the detrimental impacts of the ongoing Israeli occupation, such as the lack of sufficient follow-up care and medication. This was partly due to the economic effects of occupation on public health infrastructure. In addition, patients often could not afford medication due to increased unemployment and poverty resulting from the expropriation of land, destruction of businesses and homes, and loss of free movement for work. Lack of follow-up care and appropriate medication exacerbated the conditions of patients with chronic diseases like diabetes or hypertension. Furthermore, doctors, community health workers and nurses reported that the unremitting psychological stressors of the occupation accelerated the deteriorating effects of many chronic diseases.

Effects of the occupation also included the inability of the population to receive health screening or access to specialised care. Doctors in the study noted that rates of late cancer 
diagnosis increased due to the lack of access to primary care services; such basic services were made unavailable by economic constraints imposed by Israel, which led to the restriction of movement and crippling of health systems. Interviewees particularly noted this during 2007, when the democratic victory of Hamas resulted in the termination of aid from the United States and Israel. Even in villages serviced by mobile clinics, screening tools were simply not accessible due to the weak Palestinian economy. The previous section described the delays at checkpoints transferring a girl to specialised care; these kinds of hassles and delays were major barriers, particularly in a region known for its fragmented services.

\section{Impacts of occupation on job stress}

This research also explored the effects of negotiating the occupation for service providers themselves. A common theme was the ongoing tensions and dangers that health care providers endured to serve patients and communities. Incidents ranged from being arrested or held at gunpoint for trying to provide health care to being unexpectedly separated from family for long periods. One doctor expressed that medical providers are under constant strain because 'we don't know what will happen from moment to moment', and described 'the daily suffering in the teams from crossing checkpoints on a daily basis', which he considered a 'moral suffering, because according to international laws, we should not have to wait at checkpoints'. One medical provider discussed the anxiety that lasts well beyond one's shift:

'When we see people who are suffering, we see they are in need of help, emotional support, so many things. When we leave them and finish our work and start our evenings, we think of them. We think of their future life, of the poverty, illnesses, complications that could arise for them. This is another kind of stress when you go home and think about your people. If you go, you help them, but if you don't go, no one will help'.

Interviewees discussed how the demands of work under the continual stress of the occupation caused them to constantly readjust their personal lives. Providers carefully planned visits to get through all the checkpoints and around the road closures in time to reach their 
homes. An ambulance driver indicated that the work conditions in Palestine are such that when working, it is possible to become stranded somewhere and have to stay the night. Women in the community health worker training programme often had to be away from family for extended periods of time because travel back to their homes was too dangerous and time-consuming, or simply impossible due to closure policies. The consequences of providing health care in these circumstances did not seem to differ by gender, but slightly differential impacts were observed depending on the relative rank and class standing of the provider, as these factors represented varied power, economic and otherwise, to adapt schedules or have access to a personal vehicle.

\section{Strategies of professional perseverance}

Coping with the effects of the occupation was paramount to providing health care. One doctor stated, 'We have an exceptional ability to adapt to anything'. A central research task was to explore how this adaptation takes place. Strategies included reliance on faith and family and persistence with education, including training abroad. This appeared particularly common among younger health care workers. Among older and more senior health care workers, strategies also included efforts to establish personal relationships with officials and international partners to increase training opportunities for themselves and their team and to perhaps facilitate their work through outside advocacy. The most compelling strategy involved providers' commitment to their role as professionals and to community and team modes of delivery. When asked how he persists, one doctor had this response:

'That is a strange question. If you were in my place, you would do the same thing. You would keep working. This is a matter of doing something; helping your people. It's a matter of feeling that you are responsible and you have to do something. You are a doctor, a health provider, and you should do something to help. There are the successes to think of, and the satisfaction of the beneficiaries gives you more and more energy to continue'. 
Providers noted the importance of their belief and investment in grassroots public health strategies. Many of the doctors interviewed were leaders of health movements, and organisations like PMRS regard health as an entry point for community organising and empowerment. Providers described their involvement as a form of resistance to the ongoing occupation. This resistance began at individual levels on the part of health care providers and became a collective manner of resistance through the establishment of health committees that were part of a larger collective of various social movements. As described by a PMRS administrator and doctor:

'The major thing was to better people's lives, to provide services as an opening opportunity for them so that they may survive under the occupation. It was also an opportunity for people to organise themselves so they can resist. People found a new approach to health and wellness; [they found] the roots of wellness are social, political, environmental, and so on'.

That individual coping strategies were intimately tied to the collective sense of work and community involvement and empowerment was evident across the spectrum of workers interviewed and observed. Workers from all professional levels and backgrounds functioned as a part of professional teams. Teams were comprised of men and women, as well as a diversity of ages, regions, and religious and political orientations. Mobile clinic staff varied based on the type of clinic but usually included nurses, two doctors, lab technicians and community health workers. Trainings and debriefing sessions were conducted within the teams of workers. Through these methods, a sense of solidarity was nurtured within programmes. This also extended to cooperation between programmes; heads of programmes worked together regularly to provide mutual logistical and emotional support.

Programmes that seemed most resilient centred on principles of community-based service, and usually included the use of community health workers, who were trained in a twoyear programme and had to be nominated by and return to serve their communities. The programme increased the capacity for health care and community organising in Palestine, 
particularly in rural areas. Empowerment of women was paramount to its objectives. Mobile clinics took part in partnerships with community organisations and leaders. Community leaders arranged appointments for members of their communities and hosted the mobile clinic staff, providing them with food and help greeting patients during the operation of the mobile clinic. This team- and community-based mode of delivery was a strategy of collective problem-solving that enabled communities, organisations and individual providers to adapt to the considerable challenges with health care provision during protracted political conflict. Efforts made at each level interlocked so that the effects of occupation were manoeuvred around collectively; individual providers or communities were not left to navigate care provision in isolation.

\section{Discussion}

This research demonstrates the impacts of a military occupation, including closure policies (checkpoints, road closures), on health care providers and the provision of health services. Findings are consistent with other documentation of the interruptions to care in the Occupied Territories due to political violence and repression (United Nations General Assembly: Office of the High Commissioner and the Secretary-General 2008; World Health Organization 2008).

Results suggest that consequences to health care due to political conflict are evident in both emergency as well as primary care. Reports by doctors in this study linking the chronic stress of political conflict to diseases like diabetes and heart problems are in line with the increasing amount of knowledge about the effect of chronic stress on health (Clark et al. 2007; McEwen 2000). Results also demonstrate the considerable consequences for health care workers in terms of stress. This finding is in line with those of other studies examining secondary traumatic stress, compassion fatigue and burnout (Dominguez-Gomez and Rutledge, 2009; Gillespie and Melby, 2003). 
The study points towards the strategies that are developed by health care workers in situations of extreme duress. Collectivity emerged as a central strategy. Indeed, there is evidence that people show more favourable outcomes and are able to rally support, thus coping better, when events are framed as community events rather than individual, alienating victimisation (as found by Steinglass and Gerrity, 1990, cited Hobfoll et al. 1996). Other work has highlighted the importance of community-level strategies of resilience; this is particularly important in areas experiencing constant stress or disasters (Norris et al. 2008). Findings here on the persistence of health care workers and their use of innovative, community-centred modes of delivery suggest the critical role that health workers may play in the development of resiliency within communities. Findings also suggest the importance of organisations creating opportunities for the recognition and development of team and community strengths. In areas of ongoing political conflict or challenges to health care delivery, there may be an important role for international support and cooperation in the endeavor of supporting health care administrators in leading their teams. The topic of resilience within health care agencies and networks is increasingly important as we plan globally for organisational strength so that health care systems are better equipped in disaster situations (Rodrl̀guez and Aguirre, 2006).

There are some limitations to this study. This study provides information that is deeply contextual; although the research participants' experiences and reflections may be similar to others in the West Bank or other conflict zones, the findings are not meant to be generalised across spatial geographies or time. Interviews were limited to English, which may have restricted the types of encounters included in the analysis.

This study aids the development of a few areas of knowledge, both within the West Bank and in other conflict zones. In detailing the effects of political conflict on health care delivery 
and providers, and in suggesting support for the sequalae of chronic health consequences resulting from the stress of living under political conflict, it adds to the discussion regarding the effects of war on civilians (de Jong 2003; Giacaman et al. 2007; Murthy 2007). In particular, this research explores the ways in which acts of political violence result in the denial of access to care, thus interfering with the universal right of civilians to health care in times of war as stipulated by the fourth Geneva Convention.

These results also add to conversations about health care workforce experiences and strategies of adaptation within situations of extreme stress. The ongoing impacts of occupation necessitate creative and responsive strategies on the part of providers. One of the conclusions from this research is that health care workers can persevere and continue to provide care in the face of considerable repression. Team and community-based models of care may be particularly important to this end. Findings add to conversations about health care workforce retention and organisational resilience within health care, particularly where systems and providers are under chronic stress. Attention to systems strengthening for the shared tasks of health and statebuilding is essential for both health and peace, as previous work has amply detailed (Kruk et al. 1982). However, this research demonstrates that even visionary providers working within wellorganised programmes cannot prevail over the effects of an ongoing military occupation without fundamental changes in political arrangements and conditions.

Moving forward, this study suggests the need for external pressure on occupying forces to uphold international laws and codes of ethics during situations of war and political conflict. Impeding the ability of health workers in their attempts to deliver care is in direct conflict to the fourth Geneva Convention, which guarantees medical personnel respect and protection in occupied territories and military zones. As suggested by the World Health Organization, 
accountability to the adherence of international covenants such as the 1949 Geneva Convention is an essential step towards alleviating the burden of war and conflict on civilians (World Health Organization (WHO), 2002). Ultimately, though, solutions will not be found through either international law or through the efforts of individual health care providers or systems. International covenants and strategies of providers are important for health in the interim; however, these can never substitute for larger contexts of peace, justice, sovereignty and selfdetermination (Becker et al. 2009). Recognising war and political violence as a fundamental public health problem and regarding its prevention as a central task of health professionals is thus essential (Hagopian et al. 2009). A central role of health care providers globally might well be, then, to aid in alleviating the immediate consequences of political violence, as well as to advocate for the prevention of further violence and repression. 


\section{Acknowledgements}

The author wishes to acknowledge the Palestinian Medical Relief Society for its help and participation, especially Drs Muhammad Iskafi and Adbullah Abu Sharara. The author also wishes to acknowledge Drs Todd Herrenkohl and Taryn Lindhorst for their thoughtful and timely assistance, advice and edits.

This research was funded in part by NIMH Grant T32MH20010. 


\section{References}

Baingana, F., Bannon, I., \& Thomas, R. (2005). Mental health and conflicts: Conceptual framework and approaches. Washington, DC: The World Bank.

Becker, A., Al Ju'beh, K., \& Watt, G. (2009). Keys to health: justice, sovereignty, and selfdetermination. Lancet, 373(9668), 985-987.

CIA World Factbook. (2008, May 15 2008). West Bank. Retrieved May, 2008, from https://www.cia.gov/library/publications/the-world-factbook/geos/we.html

Clark, M. S., Bond, M. J., \& Hecker, J. R. (2007). Environmental stress, psychological stress and allostatic load. Psychology Health and Medicine, 12(1), 18-30.

de Jong, J. T. V. M. (2003). Common mental disorders in postconflict settings. The Lancet(9375), 2128-2130.

Devers, K. J. (1999). How will we know "good" qualitative research when we see it? Beginning the dialogue in health services research. Health services research, 34(5), 1153-1188.

Dominguez-Gomez, E., \& Rutledge, D. N. (2009). Prevalence of Secondary Traumatic Stress Among Emergency Nurses. JOURNAL OF EMERGENCY NURSING, 35(3), 199-204.

Giacaman, R., Abdul-Rahim, H. F., \& Wick, L. (2003). Health sector reform in the Occupied Palestinian Territories (OPT): targeting the forest or the trees? Health Policy and Planning, 18(1), 59-67.

Giacaman, R., Khatib, R., Shabaneh, L., Ramlawi, A., Sabri, B., \& Sabatinelli, G., Khawaja, M., Laurance, T. (2009). Health status and health services in the occupied Palestinian territory. The Lancet, 373(9666), 837-849.

Giacaman, R., Shannon, H. S., Saab, H., Arya, N., \& Boyce, W. (2007). Individual and collective exposure to political violence: Palestinian adolescents coping with conflict. European Journal of Public Health, 17(4), 361-368.

Gillespie, M., \& Melby, V. (2003). Burnout among nursing staff in accident and emergency and acute medicine: a comparative study. Journal of clinical nursing, 12(6), 842-851.

Hagopian, A., Ratevosian, J., \& deRiel, E. (2009). Gathering in groups: peace advocacy in health professional associations. Academic medicine : journal of the Association of American Medical Colleges, 84(11), 1485.

Hamdan, M., Defever, M., \& Abdeen, Z. (2003). Organizing health care within political turmoil: the Palestinian case. The International journal of health planning and management, 18(1), 63-87.

Herp, M. V., Parque, V., Rackley, E., \& Ford, N. (2003). Mortality, Violence and Lack of Access to Healthcare in the Democratic Republic of Congo. Disasters, 27(2), 141-153.

Hobfoll, S. E., Freedy, J. R., Green, B. L., \& Solomon, S. D. (1996). Coping in reaction to extreme stress: The roles of resource loss and resource availability. In M. Zeidner \& N. S. Endler (Eds.), Handbook of coping : theory, research, applications (pp. 322-349). New York: Wiley.

Israel Ministry of Foreign Affairs. (2004). Saving Lives: Israel's anti-terrorist fence - Answers to Questions, from http://mfa.gov.il/MFA/MFAArchive/2000_2009/2003/11/Saving+Lives+Israel-s+anti-terrorist+fence+-+Answ.htm\#1 [Accessed 30 May 2008]

Jubran, J., Al Faqih, R., Nafe, A., Khalili, S., \& Barghouthi, M. (2005). Health and Segregation II: The impact of the Israeli separation wall on access to health care services. Ramallah, Palestine: Health Development Information and Policy Institute (HDIP). . 
Kruk, M. E., Freedman, L. P., Anglin, G. A., \& Waldman, R. J. (1982). Rebuilding health systems to improve health and promote statebuilding in post-conflict countries: a theoretical framework and research agenda. Social science \& medicine, 70(1), 89-97.

Leather, A., Ismail, E. A., Ali, R., Abdi, Y. A., Abby, M. H., Gulaid, S. A., Walhad, S. A., Guleid, S., Ervine, I. M., Lowe-Lauri, M., Parker, M., Adams, S., Datema, M., Parry, E. (2006). Working together to rebuild health care in post-conflict Somaliland. Lancet, 368(9541), 1119-1125.

Marlowe, P., \& Mahmood, M. (2009). Public Health and Health Services Development in Postconflict Communities: A Case Study of a Safe Motherhood Project in East Timor. Asia-Pacific Journal of Public Health, 21(4), 469-476.

McEwen, B. S. (2000). Allostasis and Allostatic Load: Implications for Neuropsychopharmacology. Neuropsychopharmacology, 22(2), 108-124.

Murthy, R. S. (2007). Mass violence and mental health--recent epidemiological findings. International review of psychiatry (Abingdon, England), 19(3), 183-192.

Norris, F., Stevens, S., Pfefferbaum, B., Wyche, K., \& Pfefferbaum, R. (2008). Community Resilience as a Metaphor, Theory, Set of Capacities, and Strategy for Disaster Readiness. American Journal of Community Psychology, 41(1-2), 1-2.

Palestine Monitor, o. (2011, Aug. 14, 2007). Factsheet: Checkpoints, from http://www.palestinemonitor.org/spip/spip.php?article8 [Accessed 25 January 2011]

RodrÌguez, H., \& Aguirre, B. E. (2006). Hurricane Katrina and the healthcare infrastructure: A focus on disaster preparedness, response, and resiliency. Frontiers of health services management, 23(1), 13-23.

Roy, S. (1995). Gaza Strip: The political economy of de-development. Washington, D.C.: The Institute for Palestine Studies.

UNICEF. (n.d.). Statistics at a glance: Occupied Palestinian Territory, from http://www.unicef.org/infobycountry/oPt_statistics.html\#43 [Accessed 8 May 2008]

United Nations General Assembly: Office of the High Commissioner and the Secretary-General. (2008). The issue of Palestinian pregnant women giving birth at Israeli checkpoints: Report of the High Commissioner for Human Rights.

United Nations Office for the Coordination of Humanitarian Affairs (UN-OCHA)-Occupied Palestinian Territories (oPt). (2007a). Closures in the West Bank. East Jerusalem: UNOCHA OPT.

United Nations Office for the Coordination of Humanitarian Affairs (UN-OCHA)-Occupied Palestinian Territories (oPt). (2007b). The humanitarian impact on Palestinians of Israeli settlements and other infrastructure in the West Bank. East Jerusalem: UN-OCHA OPT.

United Nations Office for the Coordination of Humanitarian Affairs (UN-OCHA)-Occupied Palestinian Territories (oPt). (2008a). Humanitarian access incident report for the West Bank, oPt. East Jerusalem: UN-OCHA OPT.

United Nations Office for the Coordination of Humanitarian Affairs (UN-OCHA)-Occupied Palestinian Territories (oPt). (2008b). West Bank Territorial Fragmentation Map. East Jerusalem: UN-OCHA Occupied Palestinian Territories (oPt).

Varley, E. (2010). Targeted doctors, missing patients: obstetric health services and sectarian conflict in northern Pakistan. Social science \& medicine (1982), 70(1), 61-70.

World Health Organization. (2008). Access to health services for Palestinian people: Case studies of five patients in critical conditions who died while waiting to exit the Gaza Strip. 
World Health Organization (WHO). (2002). World Report on Violence and Health. Geneva: WHO. 


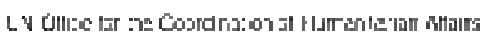

West Bank Territorial Fragmentation

Sep.ember aoub

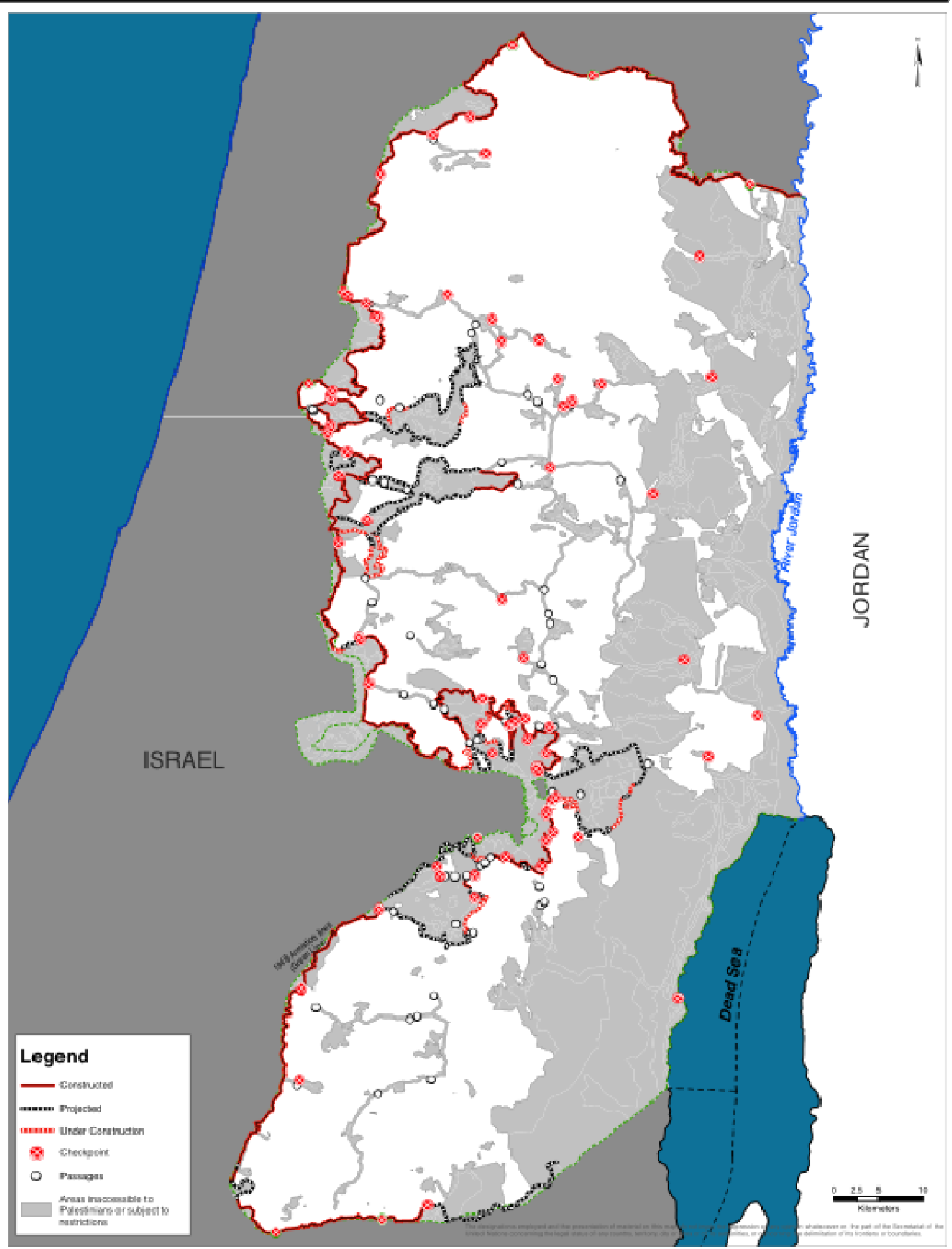




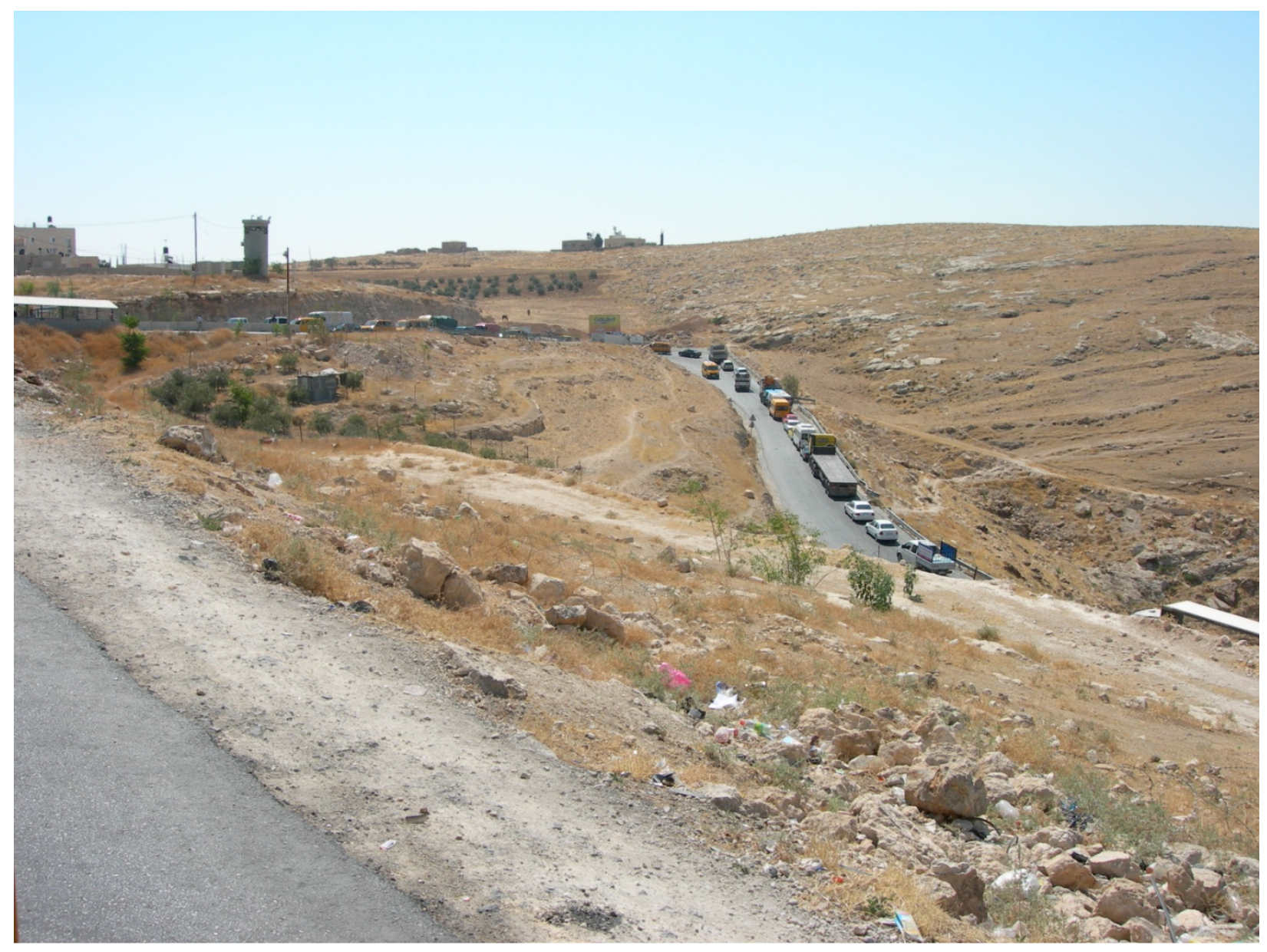




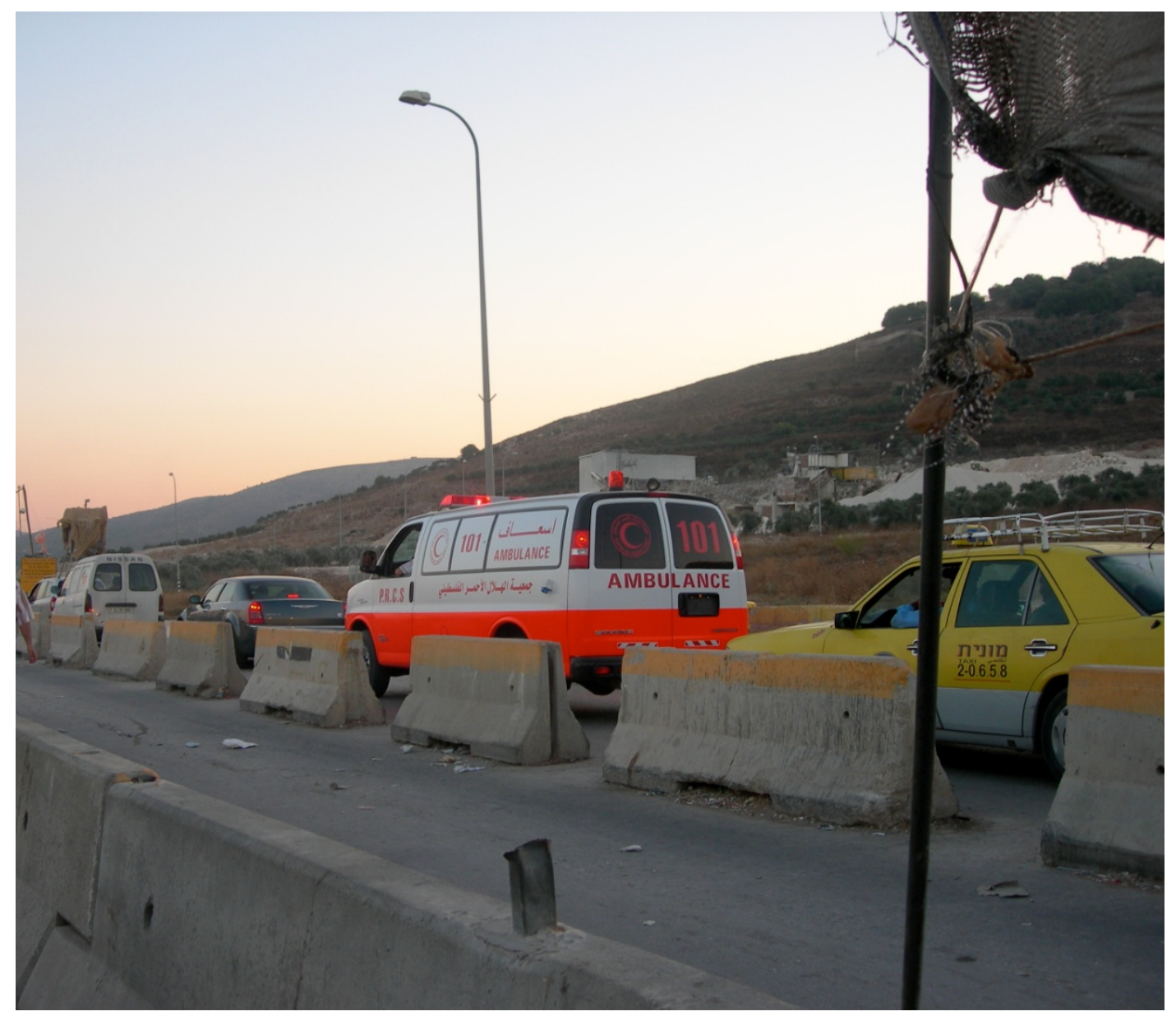

List of figures:

Figure 1: 'Fragmentation map' of the West Bank, United Nations Office for the Coordination of Humanitarian Affairs (United Nations Office for the Coordination of Humanitarian Affairs (UNOCHA)-Occupied Palestinian Territories (oPt), 2008b)

Figure 2: Line of over 50 cars waiting to pass through checkpoint. Photo credit: C. Sousa Figure 3: Ambulance blocked at checkpoint outside Nablus. Photo credit: C. Sousa 